\title{
Central Frequency of Low Frequency Component of HRV Estimates Sympathetic Activity During Dynamic Exercise, Standing and Paced Breathing Maneuvers
}

\author{
Salvador Carrasco-Sosa, Alejandra Guillén-Mandujano \\ Universidad Autónoma Metropolitana-I, CDMX, México
}

\begin{abstract}
In 25 healthy subjects we assessed the effects of the maneuvers supine position $(S)$, dynamic exercise $(D E)$, standing $(S T)$, controlled breathing $(C B)$ and $D E$ recovery $(D E R)$ on the time-courses of: central frequencies and powers of the low and high frequency components of $R R\left({ }_{C F} L F_{R R},{ }_{P} L F_{R R},{ }_{P} H F_{R R}\right)$, systolic $\left({ }_{C F} L F_{S P, P} L F_{S P}\right)$ and diastolic $\left({ }_{C F} L F_{D P},{ }_{P} L F_{D P}\right)$ pressures, estimated by a time-frequency distribution, and on the ${ }_{P} L F_{R R} /{ }_{P} H F_{R R}$ and ${ }_{C F} L F_{R R} /{ }_{P} H F_{R R}$ ratios. Relative to $S$, significant mean values changes ( $p<0.03)$ were: ${ }_{C F} L F_{R R}$ and ${ }_{P} H F_{R R}$ increased in $C B$ and decreased distinctively in $S T$ and $D E$; ${ }_{C F} L F_{R R} / P H F_{R R}$ decreased in $C B$ and increased distinctively in $S T, D E$ and $D E R ;{ }_{P} L F_{R R}$ only decreased pronouncedly in $D E$; mean $R R\left(R R_{m}\right)$ decreased in $C B, S T, D E$ and $D E R$. ${ }_{P} L F_{R R} / P H F_{R R}$ means were similar in $S T, D E$ and $D E R$. In $S, C B$, $S T$ and DER, ${ }_{C F} L F_{R R}$ was greater $(p<0.005)$ than ${ }_{C F} L F_{D P}$ and ${ }_{C F} L F_{S P}$. Correlations of ${ }_{C F} L F_{R R}$ with ${ }_{P} H F_{R R}$ and $R R_{m}$ were: $0.78 \pm 0.07$ and $0.64 \pm 0.12$ respectively. Our findings that ${ }_{C F} L F_{R R}$ : estimates the sympathetic activity $(S A)$ level of each maneuver, is strongly correlated with ${ }_{P} H F_{R R}$, improves the estimating capability of the ratio in $D E$, and is greater than ${ }_{C F} L F_{D P}$, support that ${ }_{C F} L F_{R R}$ is a trustable $S A$ indicator, relevantly in $D E$, and that the modulatory frequency of the cardiac sympathetic branch is greater than the vasomotor one.
\end{abstract}

\section{Introduction}

The leftward shift of the central frequency of the lowfrequency component $\left({ }_{C F} L F\right)$ of $R R$ series $\left({ }_{C F} L F_{R R}\right)$, as an effect provoked by maneuvers that increase sympathetic activity (SA), has been poorly studied. Active orthostatic test, head-up tilt and dynamic exercise (DE) are the provocative maneuvers more frequently used to study autonomic cardiovascular function; they cause SA increment with vagal activity (VA) reduction [1]. The leftward shift of ${ }_{\mathrm{CF}} \mathrm{LF}_{\mathrm{RR}}$ was first reported during standing condition (ST) with autonomic blockade [2]. The relation between the ${ }_{\mathrm{CF}} \mathrm{LF}_{\mathrm{RR}}$ leftward shifting produced by headup tilt with arterial pressure (AP) was studied with autoregressive modeling [3]. In a study about the effect of steady-state DE on HRV spectrum, a ${ }_{\mathrm{CF}} \mathrm{LF}_{\mathrm{RR}}$ leftward shift was found [4]. In none of the previous studies, the 1996 Task Force report on HRV [5] or a recent review of methods to study the autonomic cardiovascular function
[1], the possible use of ${ }_{\mathrm{CF}} \mathrm{LF}_{\mathrm{RR}}$ as an autonomic activity spectral estimator has been considered. Conversely, in a study about the effects of continuously increasing static exercise on ${ }_{\mathrm{CF}} \mathrm{LF}_{\mathrm{RR}}$ and on the ${ }_{\mathrm{CF}} \mathrm{LF}$ of systolic $\left({ }_{\mathrm{CF}} \mathrm{LF}_{\mathrm{SP}}\right)$ and diastolic pressures $\left({ }_{C F} L_{D P}\right)$, we provided evidence that support the performance of all ${ }_{\mathrm{CF}} \mathrm{LF}$ as adequate $\mathrm{SA}$ spectral estimators [6]. Additionally, in that same study we documented that ${ }_{\mathrm{CF}} \mathrm{LF}_{\mathrm{RR}}$ was of greater value than ${ }_{\mathrm{CF}} \mathrm{LF}_{\mathrm{SP}}$ and ${ }_{\mathrm{CF}} \mathrm{LF}_{\mathrm{DP}}$, finding attributed to functional differences between the cardiac and vasomotor sympathetic branches [6]. It has been reported that, during DE, HRV and the powers of its low frequency $\left({ }_{\mathrm{P}} \mathrm{FF}_{\mathrm{RR}}\right)$ and high frequency $\left({ }_{\mathrm{P}} \mathrm{HF}_{\mathrm{RR}}\right)$ components are reduced; therefore, ${ }_{\mathrm{P}} \mathrm{LF}_{\mathrm{RR}}$ and the derived ${ }_{\mathrm{P}} \mathrm{LF}_{\mathrm{RR}} /{ }_{\mathrm{P}} \mathrm{HF}_{\mathrm{RR}}$ ratio fail to mark the $\mathrm{SA}$ increment elicited by $\mathrm{DE}[4,7]$. We assume that: a) the maneuvers supine position $(\mathrm{S})$, controlled breathing (CB), ST and DE elicit different degrees of SA; b) SA can be assessed by the usual autonomic activity indexes; c) the study of recovery from DE (DER) allows documenting the reversibility of the effects of DE; d) the selected maneuvers affect ${ }_{C F} L_{R R}$, ${ }_{\mathrm{CF}} \mathrm{LF}_{\mathrm{SP}}$ and ${ }_{\mathrm{CF}} \mathrm{LF}_{\mathrm{DP}}$; e) ${ }_{\mathrm{CF}} \mathrm{LF}_{\mathrm{RR}}$ is strongly correlated with other autonomic activity measures; $\mathrm{f}$ ) and that in all the studied maneuvers ${ }_{\mathrm{CF}} \mathrm{LF}_{\mathrm{RR}}$ is greater than ${ }_{\mathrm{CF}} \mathrm{LF}_{\mathrm{SP}}$ and ${ }_{\mathrm{CF}} \mathrm{LF}_{\mathrm{DP}}$. To provide further support to our previously reported findings, our aims were, in 25 healthy subjects, to assess the effects of S, DE, ST, CB and DER -each maneuver lasting $5 \mathrm{~min}-$ on the time-courses of ${ }_{\mathrm{CF}} \mathrm{LF}_{\mathrm{RR}}$, ${ }_{\mathrm{CF}} \mathrm{LF}_{\mathrm{SP}}, \mathrm{CF}_{\mathrm{CF}} \mathrm{LF}_{\mathrm{DP}},{ }_{\mathrm{P}} \mathrm{LF}_{\mathrm{RR}}$, low frequency power of systolic $\left({ }_{\mathrm{P}} \mathrm{LF}_{\mathrm{SP}}\right)$, and of diastolic pressures $\left({ }_{\mathrm{P}} \mathrm{LF}_{\mathrm{DP}}\right)$, and ${ }_{\mathrm{P}} \mathrm{HF}_{\mathrm{RR}}$, all estimated by a time-frequency distribution, and on the computed ${ }_{\mathrm{P}} \mathrm{LF}_{\mathrm{RR}} /{ }_{\mathrm{P}} \mathrm{HF}_{\mathrm{RR}}$ and ${ }_{\mathrm{CF}} \mathrm{LF}_{\mathrm{RR}} /{ }_{\mathrm{P}} \mathrm{HF}_{\mathrm{RR}}$ ratios. Comparisons and correlations among spectral measures were also obtained.

\section{Methods}

\subsection{Subjects}

Twenty five healthy, nonsmoking and sedentary subjects, 14 men and 11 women, participated. Their mean age, height and weight were $22.6 \pm 2.2$ years, $164 \pm 9 \mathrm{~cm}$ and $61.4 \pm 11.2 \mathrm{~kg}$ respectively. Their written informed 
consent was requested to participate. This study was approved by the ethics committee of our university.

\subsection{Protocol}

In the first visit to the laboratory, the subjects' health status and anthropometric variables were evaluated, and in the second visit the experimental stage was carried out. The 5-min-long maneuvers employed to induce changes in SA were: $\mathrm{S}$ with spontaneous breathing, considered the control condition; ST, change from $\mathrm{S}$ to erect position; $\mathrm{CB}$ in $\mathrm{S}$ position at $0.2 \mathrm{~Hz}$ with increased tidal volume of around 2.0 liters; DE, a single bout of $100 \mathrm{~W}$ cycling exercise, and DER, sitting quietly. ECG, AP and respiration were recorded all over the session.

\subsection{Signal recording and acquisition}

ECG was detected at the thoracic bipolar lead CM5 using a bioelectric amplifier (Biopac Systems). Noninvasive AP was measured by Finapres (Ohmeda). Respirogram was obtained by a stretching pneumograph (Nihon Kohden). All signals were digitized at a sampling rate of $1 \mathrm{kHz}$ via an acquisition and display system (Biopac Systems).

\subsection{Data processing}

Fiducial points of ECG and AP recordings were detected to construct the RR, systolic pressure (SP) and diastolic pressure (DP) time series, which were cubicspline interpolated, resampled at $4 \mathrm{~Hz}$ and detrended. Time-frequency spectra of the series were estimated with the smoothed pseudo-Wigner-Ville distribution and their first two-order moments were computed in the standard low and high frequency bands to obtain the instantaneous time courses of ${ }_{\mathrm{P}} \mathrm{LF}_{\mathrm{RR}},{ }_{\mathrm{P}} \mathrm{LF}_{\mathrm{SP}},{ }_{\mathrm{P}} \mathrm{LF}_{\mathrm{DP}},{ }_{\mathrm{P}} \mathrm{HF}_{\mathrm{RR}},{ }_{\mathrm{CF}} \mathrm{LF}_{\mathrm{RR}}$, ${ }_{\mathrm{CF}} \mathrm{LF}_{\mathrm{SP}}$ and ${ }_{\mathrm{CF}} \mathrm{LF}_{\mathrm{DP}}$. The ${ }_{\mathrm{P}} \mathrm{LF}_{\mathrm{RR}} / \mathrm{P}_{\mathrm{P}} \mathrm{HF}_{\mathrm{RR}}$ and ${ }_{\mathrm{CF}} \mathrm{LF}_{\mathrm{RR}} / \mathrm{P}_{\mathrm{P}} \mathrm{HF}_{\mathrm{RR}}$ ratios were computed.

\subsection{Statistical analysis}

Data are expressed as mean \pm SD. Intermaneuver and intervariable mean values comparisons were performed with ANOVA for repeated measures. Post-hoc pairwise comparisons were performed by the Tukey test. 50-s epochs of the variables dynamics were used to compute subject-by-subject correlations and regressions of ${ }_{C F} L_{R R}$ with ${ }_{\mathrm{P}} \mathrm{HF}_{\mathrm{RR}}$ and mean $\mathrm{RR}\left(\mathrm{RR}_{\mathrm{m}}\right)$. Statistical significance was set at $\mathrm{p}<0.05$.

\section{Results}

Relative to $\mathrm{S}$, mean values of: ${ }_{\mathrm{CF}} \mathrm{LF}_{\mathrm{RR}}$ increased in $\mathrm{CB}$ $(\mathrm{p}<0.03)$ and decreased in ST $(\mathrm{p}<0.001)$ and DE $(\mathrm{p}<0.001)$ but were similar in DER (Fig. 1A), with a range of frequency shift across maneuvers of $25 \mathrm{mHz}$; ${ }_{\mathrm{CF}} \mathrm{LF}_{\mathrm{SP}}$ and ${ }_{\mathrm{CF}} \mathrm{LF}_{\mathrm{DP}}$ showed similar changes across the maneuvers, increasing in CB, ST and DER $(p<0.003$, Fig. $1 B-C)$, with a shift range of $5 \mathrm{mHz}$. The mean values of ${ }_{\mathrm{CF}} \mathrm{LF}_{\mathrm{RR}}$ were greater $(\mathrm{p}<0.003)$ than those of ${ }_{\mathrm{CF}} \mathrm{LF}_{\mathrm{DP}}$ in $\mathrm{S}$ $(10 \pm 5 \mathrm{mHz}), \mathrm{CB}(15 \pm 5 \mathrm{mHz}), \mathrm{ST}(3 \pm 3 \mathrm{mHz})$ and DER $(4 \pm 4 \mathrm{mHz})$, but were similar in $\mathrm{DE}(0 \pm 3 \mathrm{mHz})$ (Fig. 1).

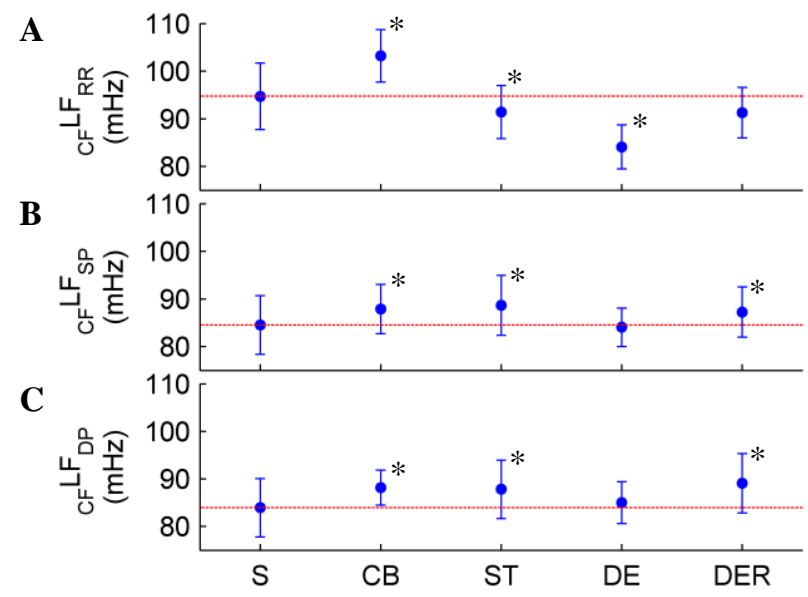

Fig. 1. Mean \pm SD of: A) $\left.\left.{ }_{C F} L_{\text {RR }}, B\right){ }_{C F} L F_{S P}, C\right){ }_{C F} L F_{D P}$ during the 5 maneuvers. ${ }^{*} \mathrm{p}<0.03$ vs. $\mathrm{S}$.

Relative to $\mathrm{S}$ condition, mean values of: ${ }_{\mathrm{P}} \mathrm{LF}_{\mathrm{RR}}$ only decreased pronouncedly in DE ( $\mathrm{p}<0.001$, Fig. $2 \mathrm{~A}),{ }_{\mathrm{P}} \mathrm{LF}_{\mathrm{SP}}$ and ${ }_{\mathrm{P}} \mathrm{LF}_{\mathrm{DP}}$ displayed parallel changes across maneuvers, did not change in $\mathrm{CB}$ and increased in ST, DE and DER $\left(\mathrm{p}<0.03\right.$, Fig. 2B-C); ${ }_{\mathrm{P}} \mathrm{HF}_{\mathrm{RR}}$ increased in $\mathrm{CB}$ and decreased in ST, DE and DER ( $p<0.001$, Fig. 2D).

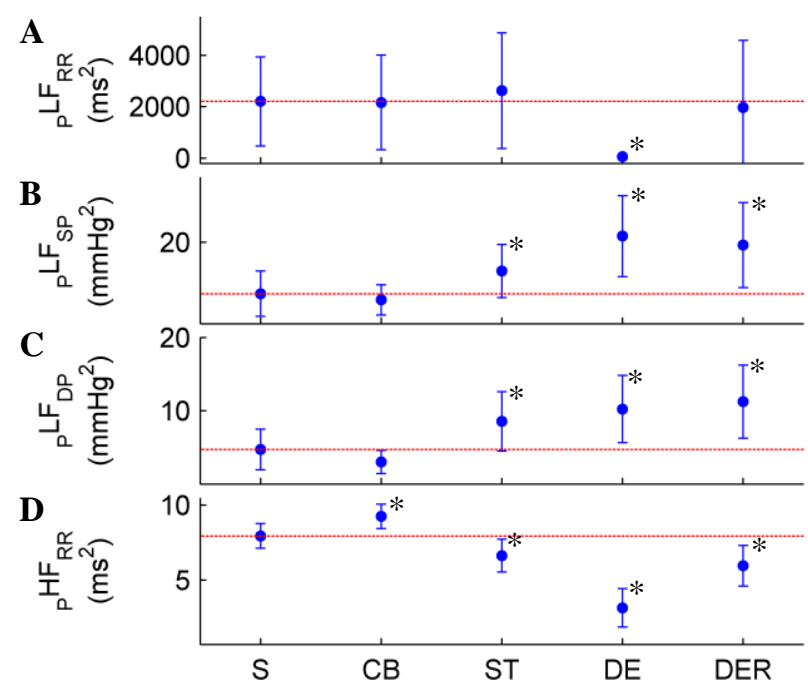

Fig. 2. Mean \pm SD of: A) $\left.\left.\left.{ }_{\mathrm{P}} \mathrm{LF}_{\mathrm{RR}}, \mathrm{B}\right){ }_{\mathrm{P}} \mathrm{LF}_{\mathrm{SP}}, \mathrm{C}\right){ }_{\mathrm{P}} \mathrm{LF}_{\mathrm{DP}}, \mathrm{D}\right)$ ${ }_{\mathrm{P}} \mathrm{HF}_{\mathrm{RR}}$ during the 5 maneuvers. ${ }^{*} \mathrm{p}<0.03$ vs. $\mathrm{S}$. 
With respect to $S$, mean values of: $R R_{m}$ decreased in CB, ST, DE and DER ( $<<0.01$, Fig. 3A); ${ }_{\mathrm{P}} \mathrm{FF}_{\mathrm{RR}} /{ }_{\mathrm{P}} \mathrm{HF}_{\mathrm{RR}}$ decreased in CB $(p<0.01)$ and increased in ST, DE and DER ( $\mathrm{p}<0.005)$, but were similar in ST and DE (Fig. 3B); ${ }_{\mathrm{CF}} \mathrm{LF}_{\mathrm{RR}} / \mathrm{PHF}_{\mathrm{RR}}$ decreased in $\mathrm{CB}(\mathrm{p}<0.03)$ and increased in ST $(p<0.01)$, DE $(p<0.001)$ and DER $(p<0.001)$ (Fig. 3C).

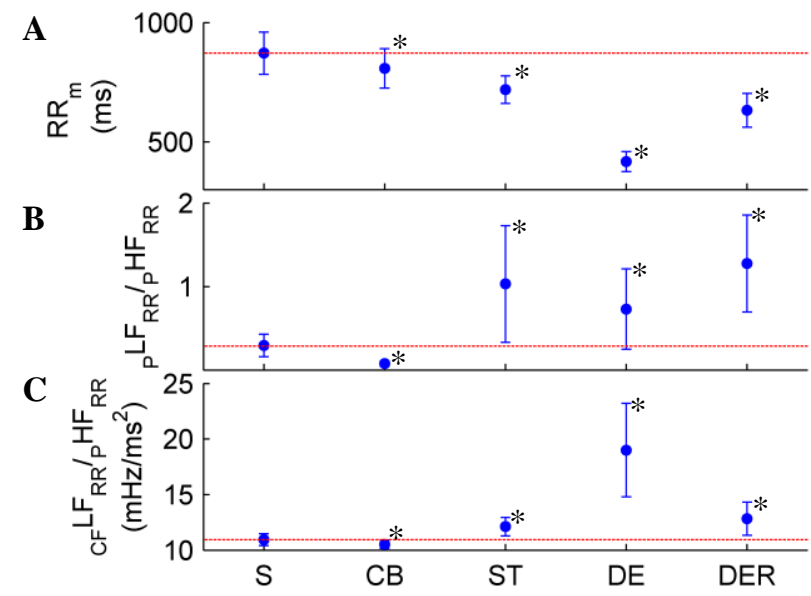

Fig. 3. Mean \pm SD of: A) $R_{m}$, B) $\left.{ }_{P} L F_{R R} /{ }_{P} H F_{R R}, C\right)$ ${ }_{\mathrm{CF}} \mathrm{LF}_{\mathrm{RR}} /{ }_{\mathrm{P}} \mathrm{HF}_{\mathrm{RR}}$ during the 5 maneuvers. ${ }^{*} \mathrm{p}<0.03$ vs. $\mathrm{S}$.

For ${ }_{\mathrm{P}} \mathrm{HF}_{\mathrm{RR}}, \mathrm{RR}_{\mathrm{m}}$ and ${ }_{\mathrm{CF}} \mathrm{LF}_{\mathrm{RR}} /{ }_{\mathrm{P}} \mathrm{HF}_{\mathrm{RR}}$, all of the paired mean comparisons among the five maneuvers were different $(\mathrm{p}<0.01)$. The mean values of all measures presented large SD values, indicative of high intersubject response variation.

The mean correlation of ${ }_{\mathrm{CF}} \mathrm{LF}_{\mathrm{RR}}$ with ${ }_{\mathrm{p}} \mathrm{HF}_{\mathrm{RR}}$ was $0.78 \pm 0.07$ ( $\mathrm{p}<0.001$, Fig. 4A) and with $\mathrm{RR}_{\mathrm{m}}$ was $0.64 \pm 0.12$ ( $<<0.01$, Fig. 4B).
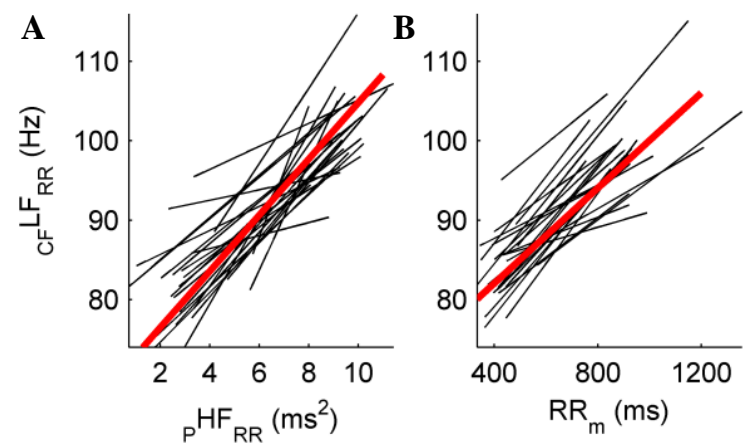

Fig. 4. Mean linear regression (red) computed from the individual regressions (black) between ${ }_{\mathrm{CF}} \mathrm{LF}_{\mathrm{RR}}$ and: $\mathrm{A}$ ) $\left.{ }_{\mathrm{P}} \mathrm{HF}_{\mathrm{RR}}, \mathrm{B}\right) \mathrm{RR}_{\mathrm{m}}$.

\section{Discussion}

Using five maneuvers that provoke distinct degrees of $\mathrm{SA}$, as estimated by the usual robust autonomic indexes, ${ }_{\mathrm{P}} \mathrm{HF}_{\mathrm{RR}}$ and $\mathrm{RR}_{\mathrm{m}}$, we provide evidence that ${ }_{\mathrm{CF}} \mathrm{LF}_{\mathrm{RR}}$, in a relevant fashion and, to a lesser degree, ${ }_{\mathrm{CF}} \mathrm{LF}_{\mathrm{SP}}$ and ${ }_{\mathrm{CF}} \mathrm{LF}_{\mathrm{DP}}$, present distinctive changes that are inversely proportional to the SA level, which makes their use as quantitative SA estimators feasible. Our main findings are: 1) with respect to $S$, the mean values of: ${ }_{C F} L F_{R R}$ and ${ }_{\mathrm{P}} \mathrm{HF}_{\mathrm{RR}}$ increase in $\mathrm{CB}$ and decrease distinctively in ST and $\mathrm{DE}$ (Fig. 2A and 3D); ${ }_{\mathrm{P}} \mathrm{LF}_{\mathrm{RR}}$ only decreases pronouncedly in $\mathrm{DE} ;{ }_{\mathrm{CF}} \mathrm{LF}_{\mathrm{SP}}$ and ${ }_{\mathrm{CF}} \mathrm{LF}_{\mathrm{DP}}$ augment in $\mathrm{CB}$, ST and DER (Fig. 2 B-C); $\mathrm{RR}_{\mathrm{m}}$ decreased in CB, ST, DE and DER (Fig. 3A); the ${ }_{\mathrm{CF}} \mathrm{LF}_{\mathrm{RR}} / \mathrm{PHF}_{\mathrm{RR}}$ ratio decrease in $\mathrm{CB}$ and increase distinctively in ST, DE and DER (Fig. $4 \mathrm{C}) ;{ }_{\mathrm{P}} \mathrm{LF}_{\mathrm{RR}} /{ }_{\mathrm{P}} \mathrm{HF}_{\mathrm{RR}}$ ratio increased in $\mathrm{ST}, \mathrm{DE}$ and DER but with similar mean values (Fig.4B); ${ }_{\mathrm{P}} \mathrm{LF}_{\mathrm{SP}}$ and ${ }_{\mathrm{P}} \mathrm{LF}_{\mathrm{DP}}$ increased distinctively in S, DE and DER (Fig. 3B-C). 2) ${ }_{\mathrm{CF}} \mathrm{LF}_{\mathrm{RR}}$ presents strong correlations with ${ }_{\mathrm{P}} \mathrm{HF}_{\mathrm{RR}}$ and $\mathrm{RR}_{\mathrm{m}}$ (Fig. 5). 3) ${ }_{C F} L_{\mathrm{RR}}$ mean values are greater than those of ${ }_{\mathrm{CF}} \mathrm{LF}_{\mathrm{DP}}$ in $\mathrm{S}, \mathrm{CB}, \mathrm{ST}$ and DER but similar in DE (Fig. 2).

$\mathrm{CB}$ at $0.2 \mathrm{~Hz}$ elicits, possibly via central command, an increase of VA [1], although its associated SA degree has not been reported. In our study and in relation to $S$, considered as the baseline condition for $\mathrm{SA}$ and ${ }_{\mathrm{CF}} \mathrm{LF}_{\mathrm{RR}}$, $\mathrm{CB}$ shifted ${ }_{\mathrm{CF}} \mathrm{LF}_{\mathrm{RR}} 11 \mathrm{mHz}$ to the right, raising its level to a maximum, without significantly changing ${ }_{\mathrm{P}} \mathrm{LF}_{\mathrm{RR}}$, which, associated to the also maximal ${ }_{\mathrm{P}} \mathrm{HF}_{\mathrm{RR}}$, suggests that $\mathrm{CB}$ induces the minimal SA degree. This finding is relevant because only the maneuver-induced leftward shifts of ${ }_{\mathrm{CF}} \mathrm{LF}_{\mathrm{RR}}$ have been reported.

There is agreement in that ST causes, via baroreflex activation, a SA increment for the adaptive adjustment of the cardiovascular response to the postural change [1]. The ${ }_{\mathrm{CF}} \mathrm{LF}_{\mathrm{RR}}$ leftward shift was first documented during ST, accentuated by low-dose atropine, and was attributed to the VA reduction that this maneuver produces [2], although later it was found to be independent of respiratory frequency changes [8]. Also, the ${ }_{C F} L F_{R R}$ leftward shift provoked by head-up tilt has been ascribed to the AP resonance loop [3]. Our findings corroborate that ST elicited a 4-mHz leftward shift of ${ }_{\mathrm{CF}} \mathrm{LF}_{\mathrm{RR}}$, whose value is consistent with those achieved by ${ }_{\mathrm{P}} \mathrm{HF}_{\mathrm{RR}}$ and ${ }_{\mathrm{P}} \mathrm{LF}_{\mathrm{SP}}$, assessing the $\mathrm{SA}$ degree provoked by $\mathrm{ST}$ to a level between those of $\mathrm{S}$ and DE.

The ${ }_{\mathrm{CF}} \mathrm{LF}_{\mathrm{RR}}$ leftward shift reported during $\mathrm{DE}$ has also been attributed to the VA fall caused by this maneuver [4]. In our study, the maximal ${ }_{\mathrm{CF}} \mathrm{LF}_{\mathrm{RR}}$ leftward shift is attained during $\mathrm{DE}(11 \mathrm{mHz})$, which, together with the minimal levels of ${ }_{\mathrm{P}} \mathrm{HF}_{\mathrm{RR}}$ and $\mathrm{RR}_{\mathrm{m}}$, and in agreement with the 4:1 SA/VA proportion reported [9], allows to qualify the SA degree elicited by DE as the maximal among the studied maneuvers. During $\mathrm{DE},{ }_{\mathrm{P}} \mathrm{LF}_{\mathrm{RR}}$ decreases sharply [4]; consequently, the ${ }_{\mathrm{P}} L F_{\mathrm{RR}} / \mathrm{P}_{\mathrm{P}} \mathrm{HF}_{\mathrm{RR}}$ ratio is also reduced and neither of them marks the expected large SA increase induced by $\mathrm{DE}$ [7]. In contrast, when we pragmatically replace the minimized ${ }_{\mathrm{P}} \mathrm{LF}_{\mathrm{RR}}$ with the maximized ${ }_{\mathrm{CF}} \mathrm{LF}_{\mathrm{RR}}$ for computing an alternative index of the sympathovagal balance, the ${ }_{\mathrm{CF}} \mathrm{LF}_{\mathrm{RR}} / \mathrm{PHF}_{\mathrm{RR}}$ ratio adequately distinguishes and assesses the level of SA in DE as maximal. 
Our findings corroborate the ${ }_{\mathrm{CF}} \mathrm{LF}_{\mathrm{RR}}$ leftward shift in DE reported by others, but we disagree with their notion that it is caused by the VA reduction both in this maneuver and in ST [2, 8, 4]. Instead, we attribute it to the SA increment provoked by these maneuvers. This explanation is further supported by the shift of ${ }_{\mathrm{CF}} \mathrm{LF}_{\mathrm{DP}}$, in which VA does not participate, only vasomotor SA.

After the termination of DE, SA and VA tend to return to their baseline values. In this study, ${ }_{C F} L F_{R R}$ shows a return to its baseline in accordance with the tendency presented by ${ }_{\mathrm{P}} \mathrm{HF}_{\mathrm{RR}}, \mathrm{RR}_{\mathrm{m}}$ and ${ }_{\mathrm{P}} \mathrm{LF}_{\mathrm{SP}}$, further documenting the reversibility of the maximal ${ }_{C F} L F_{R R}$ leftward shift provoked by DE [4].

In a previous study we reported that ${ }_{\mathrm{CF}} \mathrm{LF}_{\mathrm{RR}},{ }_{\mathrm{CF}} \mathrm{LF}_{\mathrm{SP}}$ and ${ }_{C F} L_{D P}$ shifted leftwards in response to the progressive increment of SA produced by continuously increasing static exercise [6]. We now extend these findings to DE, a maneuver that elicits SA increment and VA reduction via the central command, provoking important heart rate increment and HRV reduction in both low and high frequency bands [9].

Taken together, the evidence previously reported by us and by others, as well as the one provided by this study, support the adequate performance of ${ }_{\mathrm{CF}} \mathrm{LF}$ as indexes of the cardiovascular autonomic activity, although their specificity for SA or VA has not been convincingly demonstrated yet, requiring further study. However, our findings suggest that ${ }_{C F} L F_{R R}$ distinctly evaluates the $\mathrm{SA}$ level evoked by each maneuver, and that its variations are inversely proportional to $\mathrm{SA}$, properties that support the possible use of ${ }_{\mathrm{CF}} \mathrm{LF}_{\mathrm{RR}}$ as a reliable $\mathrm{SA}$ spectral measure.

Our findings also document that the studied maneuvers, significantly $\mathrm{CB}$ and $\mathrm{ST}$, affected ${ }_{\mathrm{CF}} \mathrm{LF}_{\mathrm{SP}}$ and ${ }_{\mathrm{CF}} \mathrm{LF}_{\mathrm{DP}} \cdot{ }_{\mathrm{CF}} \mathrm{LF}_{\mathrm{RR}}$, with respect to ${ }_{\mathrm{CF}} \mathrm{LF}_{\mathrm{DP}}$, presents: greater dynamic range across the maneuvers, stronger correlations with ${ }_{\mathrm{P}} \mathrm{HF}_{\mathrm{RR}}$ and $\mathrm{RR}_{\mathrm{m}}$, and greater values in $\mathrm{S}$, $\mathrm{CB}, \mathrm{ST}$ and DER but similar values in DE. This last difference corroborates our previous finding that, during control, in the stages prior to the maximum and during the recovery from static exercise, ${ }_{C F} L_{R R}$ was greater than ${ }_{\mathrm{CF}} \mathrm{LF}_{\mathrm{DP}}$, but was similar at the maximal intensity of static exercise, where SA achieves its maximum [6]. This finding was roughly attributed to functional differences between the cardiac and vasomotor sympathetic branches.

Based on the modulation in the low frequency band presented by the SA, which corresponds to those of the HRV and AP variability spectra [10], a possible explanation of the larger ${ }_{\mathrm{CF}} \mathrm{LF}_{\mathrm{RR}}$ and its greater range of shift than ${ }_{\mathrm{CF}} \mathrm{LF}_{\mathrm{DP}}$ is that both the ${ }_{\mathrm{CF}} \mathrm{LF}$ and the shift range of the cardiac sympathetic branch are larger than those of the vasomotor sympathetic branch. Thus, ${ }_{\mathrm{CF}} \mathrm{LF}_{\mathrm{RR}}$ and ${ }_{\mathrm{CF}} \mathrm{LF}_{\mathrm{DP}}$ possibly estimate the frequency modulation properties presented by SA in its cardiac and vasomotor branches respectively.

In conclusion, our findings: 1) the progressive ${ }_{\mathrm{CF}} \mathrm{LF}_{\mathrm{RR}}$ decrease from a maximum obtained in $\mathrm{CB}$ followed by $\mathrm{S}$ to a minimum in DE and its return to baseline in DER, 2) the strong correlation between ${ }_{C F} L_{\mathrm{RR}}$ with the robust autonomic markers ${ }_{\mathrm{P}} \mathrm{HF}_{\mathrm{RR}}$ and $\mathrm{RR}_{\mathrm{m}}$ and 3) the different levels of $\mathrm{SA}$ elicited by the maneuvers are better discriminated by ${ }_{\mathrm{CF}} \mathrm{LF}_{\mathrm{RR}} / \mathrm{P}_{\mathrm{P}} \mathrm{HF}_{\mathrm{RR}}$ than by ${ }_{\mathrm{P}} \mathrm{LF}_{\mathrm{RR}} /{ }_{\mathrm{P}} \mathrm{HF}_{\mathrm{RR}}$ ratio, support that ${ }_{\mathrm{CF}} \mathrm{LF}_{\mathrm{RR}}$ performs adequately as a quantitative SA estimator, relevantly in $\mathrm{DE}$, and that it could replace ${ }_{\mathrm{P}} \mathrm{LF}_{\mathrm{RR}}$ for computing the sympathovagal balance. The striking finding that ${ }_{C F} L_{R R}$ is greater than ${ }_{\mathrm{CF}} \mathrm{LF}_{\mathrm{DP}}$ in $\mathrm{S}, \mathrm{CB}, \mathrm{ST}$ and DER, although similar in DE, suggests that the cardiac SA presents greater modulating frequency than the vasomotor SA, evidences that strengthen our previously reported notions.

\section{References}

[1] Ziemssen T, Siepmann T. The Investigation of the cardiovascular and sudomotor autonomic nervous system. Front Neurol 2019; doi:10.3389/fneur.2019.00053.

[2] Weise F, Heydenreich F, Runge U. Contributions of sympathetic and vagal mechanisms to the genesis of heart rate fluctuations during orthostatic load: a spectral analysis. J Auton Nerv Sys 1987; 21:127-134.

[3] Raymond B, Mazumdar J, Nandagopal D. Modelling the shift of the low frequency component of heart rate variability. Comput Cardiol 1997; 24:407-410.

[4] Kamath M, Fallen E, McKelvie R. Effects of steady state exercise on the power spectrum of heart rate variability. Med Sci Sports Exerc 1991; 23:428-434.

[5] Task Force of the European Society of Cardiology and the North American Society of Pacing and Electrophysiology. Heart rate variability standards of measurement, physiological interpretation, and clinical use. Eur Heart J 1996; 17: 354-381.

[6] Guillén-Mandujano A, Carrasco-Sosa S. Time courses of central frequencies of low frequency components of systolic and diastolic pressures and RR intervals variabilities in response to incremental isometric exercise. Comput Cardiol 2019; 10.23919/CinC49843.2019.9005895

[7] Eckberg D. Sympathovagal balance: a critical appraisal. Circulation 1997; 96:3224-3232.

[8] Weise F, Heydenreich F. Effects of modified respiratory rhythm on heart rate variability during active orthostatic load. Biomed Biochim Acta 1989; 48:549-556.

[9] White D, Raven P. Autonomic neural control of heart rate during dynamic exercise: revisited. J Physiol 2014; 592: 2491-2500.

[10]Furlan R, Porta A, Costa F, Tank J, et al. Oscillatory patterns in sympathetic neural discharge and cardiovascular variables during orthostatic stimulus. Circulation 2000; 101:886-892.

Address for correspondence.

Alejandra Guillén-Mandujano

Depto. Ciencias de la Salud, T-172.

UAM-I, CDMX, México.

ale.guillen.mandujano@gmail.com 